\title{
Acute Hemiparesis and Ipsilateral Supratentorial Lesion: Any Association?
}

Amin OSM

Neurologist, Department of Neurology, Sulaimaniya General Teaching Hospital, Sulaimaniya City, Iraq

Quiz:

A 59-year-old man presented with acute grade 4 left-sided pyramidal weakness, which improved spontaneously over a half-an-hour period to a remarkable degree. He had a history of longstanding hypertension and hyperlipidemia for which he was taking daily ramipril and atorvastatin. Otherwise, he denied any history of headache, previous focal neurological deficits, or seizures. He reported no loss of consciousness or external injuries. After examining the patient, an urgent non-contrast CT brain scan was carried out (Figure).

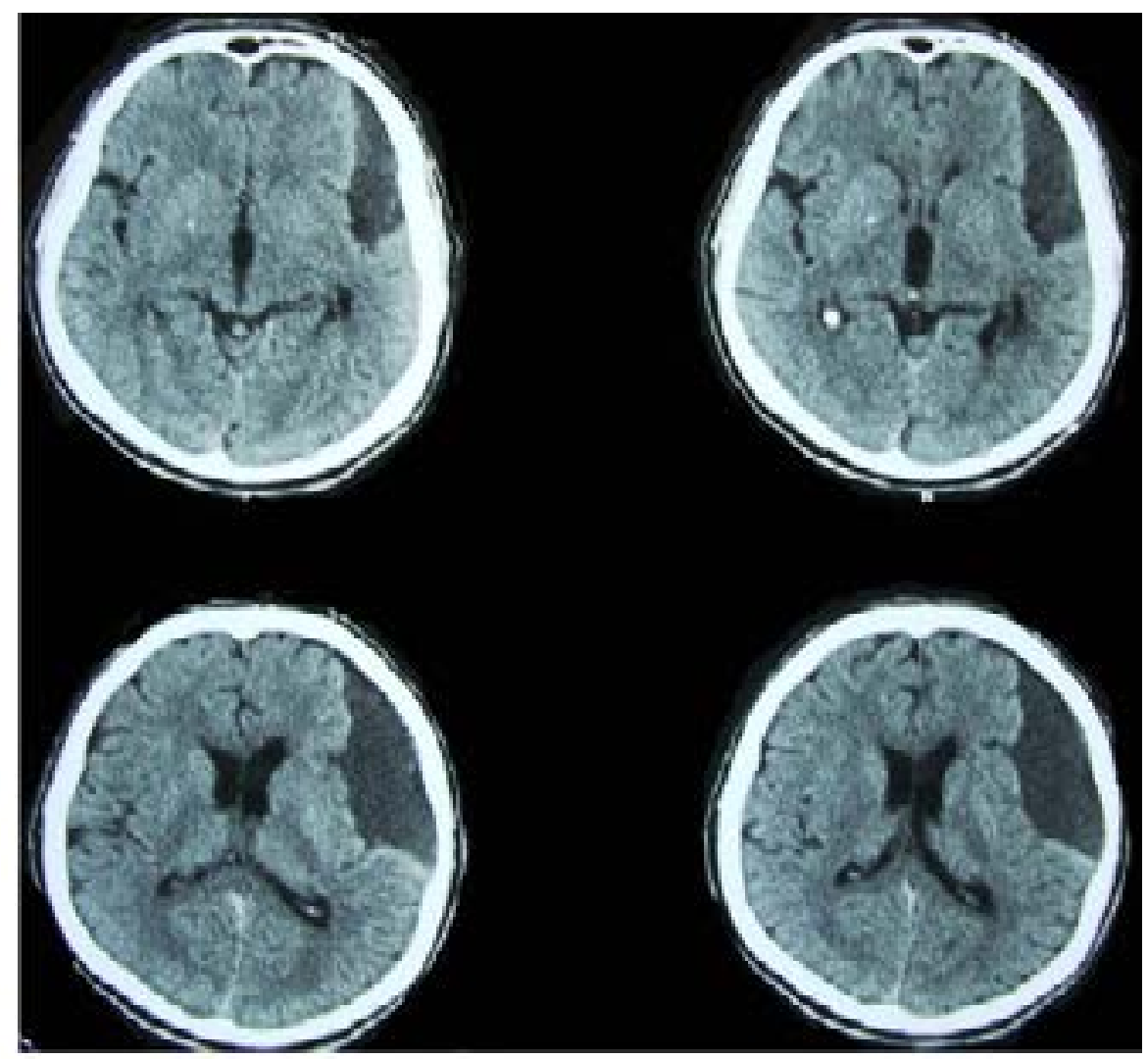

1. What was the likely cause of his hemiparesis?

E. Acute right-sided intra-occipital horn/ventricular haemorrhage.

A. Chronic left-sided extradural hematoma.

B. Subacute left-sided subdural hematoma.

C. Right-sided hemispheric transient ischemic attack.

D. Small right-sided basal ganglia haemorrhage.

Answer: C

Corresponding author:

Osama Shukir Muhammad Amin

$M D, M R C P I$, MRCPS (Glasg), FCCP, FACP

Sulaimaniya Post-Office, PO BOX 196,

Sulaimaniya City, Iraq

2. What is the next best step?

Tel: 009647703515964

Fax: 0014133047585

E-mail:dr.osama.amin@gmail.com

A. Arrange for urgent craniectomy.

B. Do burr-hole craniotomy.

C. Prescribe aspirin.

D. Order direct ventriculostomy.

E. Check coagulation profile.

Answer: C 


\section{DISCUSSION}

Clinically, this middle-aged hypertensive and hyperlipidemic man had a hemispheric TIA; he should receive antiplatelet therapy, like aspirin. The left-sided "extra-axial" hypodense area in the CT is an arachnoid cyst, which was an incidental finding. Superficially, its shape resembles a large extradural hematoma; but there is no such a "chronic" hematoma. Extradural and subdural hematomas compress the underlying brain and result in effacement of its sulci and ventricles with midline shifting of the hemispheric structures which is not seen in this case. The hyperdense areas inside the right basal ganglia and occipital horn are calcifications.

Arachnoid cysts comprise approximately $1 \%$ of all intracranial space occupying lesions and develop when CSF collects between layers of the arachnoid matter of the meninges. The majority of these cysts are "primary" and result from abnormal development of the brain meninges in utero; however, some cysts are acquired and result from loculation of CSF within the arachnoid layers as an aftermath of inflammatory adhesions. Around $42 \%$ are found supratentorially; of these, $5 \%$ are located on one of the hemispheres. The wide-spread use of brain imaging has uncovered the presence of several arachnoid cysts; most of these cysts in adults are asymptomatic while in children they usually result in epilepsy, focal deficits, and cognitive impairment. This man had no symptoms with respect to his cyst so he needs no neurosurgical intervention.

\section{FURTHER READING}

1. Amin OSM, Shwani SS. Asymptomatic supratentorial arachnoid cyst and symptomatic demyelination plaques: which one needstreatment? BMJ Case Reports 2010;10.1136/bcr.08.2010.3286.

2. Pascual-Castroviejo I, Roche MC, Martínez Bermejo A, Arcas J, García Blázquez M. Primary intracranial arachnoidal cysts. A study of 67 childhood cases. Childs Nerv Syst 1991;7:257-63.

3. Dyck P, Gruskin P. Supratentorial arachnoid cysts in adults. A discussion of two cases from a pathophysiologic and surgical perspective. Arch Neurol 1977;34:276-9. 